\title{
PEMANFAATAN KARBON AKTIF DARI SERBUK KAYU MERBAU DAN TONGKOL JAGUNG SEBAGAI ADSORBEN UNTUK PENGOLAHAN LIMBAH CAIR AAS
}

\author{
Eddyanto Winoto $^{1}$, Surya Hatina ${ }^{2}$, Sobirin ${ }^{3}$ \\ ${ }^{123)}$ Program Studi Teknik Kimia Universitas Tamansiswa Palembang \\ Jl. Tamansiswa No.261, 20 Ilir D. I, Ilir Tim. I, Kota Palembang \\ ${ }^{1)}$ eddyantowinoto24@gmail.com ; \\ ${ }^{2)}$ surya.hatina@gmail.com
}

Uji efektivitas dari karbon aktif dengan memanfataatkan limbah biomassa ini menggunakan perbandingan temperatur karbonisasi dan konsentrasi aktivator $\mathrm{H} 2 \mathrm{SO} 4$. Dimana waktu pemanasan karbonisasi yaitu selama 1 jam sementara variasi temperatur karbonisasi adalah $200^{\circ} \mathrm{C}, 250^{\circ} \mathrm{C}, 300^{\circ} \mathrm{C}$, $350^{\circ} \mathrm{C}$ dan $400^{\circ} \mathrm{C}$ dengan konsentasi aktivator $0.5 \mathrm{M}, 2,0 \mathrm{M}$ dan 3,0M. Tujuan dari penelitian ini adalah untuk mengetahui daya serap karbon aktif terhadap limbah sehingga dapat menurunkan kandungan logam dan menetralkan $\mathrm{pH}$ pada limbah AAS sesuai dengan data baku mutu Baku mutu limbah cair kementrian negara lingkungan hidup No. KEP-51/MENLH/10/1995. Karbon aktif yang dihasilkan pada limbah : $\mathrm{pH}$ awal 0,34 dan variabel yang mendekati $\mathrm{pH}$ dengan baku mutu limbah cair kementrian negara lingkungan hidup No. KEP-51/MENLH/10/1995 yaitu 6,0-9,0, Fe awal 23,11 mg/L dan $350-400{ }^{\circ} \mathrm{C}$ dan konsentrasi 0,5M, 2,0M, 3,0 M dengan berkisar 9,45-5,46 mg/L, Fe limbah awal 23,11 mg/L dan pada baku mutu limbah cair kementrian negara lingkungan hidup No. KEP51/MENLH/10/1995 sebesar $10 \mathrm{mg} / \mathrm{L}$.

Kata Kunci :Karbon Aktif, Serbuk Kayu Merbau, Tongkol Jagung

\section{PENDAHULUAN}

Pencemaran lingkungan merupakan salah satu faktor rusakanya lingkungan yang akan berdampak pada makhluk hidup disekitarnya. Sumber pencemaran lingkungan diantaranya berasal dari air, tanah, dan udara. Salah satu faktor pencemaran tersebut disebabkan oleh limbah yang berasal dari industri, domestic, pertanian laboraturium dan lain sebagainya. Limbah adalah cairan, padatan dan gas dalam suatu wilayah atau tempat tertentu yang mengalami penyimpanan dari keadaan normal akibat adanya bahan-bahan kimia yang telah dipergunakan untuk berbagaikegiatan.

Limbah cair laboraturium hingga saat ini belum mendapat perhatian yang memadai, dari sisi jumlah, limbah cair yang dihasilkan oleh suatu laboraturium umumnya memang relative sedikit, akan tetapi limbah cair tercemar berat oleh berbagai jenis bahan oraganik dan logam berat. Secara kolektif dan dalam kurun waktu yang lama dapat berdampak nyata pada lingkungan apabila tidak dikelola secara memadai, karena bahan organik dan logam berat tersebut akan terakumulasi.

Limbah laboratorium yang dihasilkan merupakan campuran dari berbagai reaksi dan sisa sampel praktikum dan penelitian dengan parameter yang melebihi baku mutu berdasarkan Peraturan Menteri Lingkungan Hidup Republik Indonesia No.5 Tahun 2014 yaitu COD, Pb, Fe. Menurut 
penelitian Fajarwati, dkk (2012) karbon aktif mampu menurunkan logam besi sebesar 59,64\% dari $3,03 \mathrm{mg} / \mathrm{l}$ menjadi $1,22 \mathrm{mg} / \mathrm{l}$, dan menaikkan $\mathrm{pH}$ dari 5,1 menjadi 9,33, serta dapat menyerap warna dalam pengolahan air tanah.Limbah cair dari PT. Geoservices terutama pada limbah AAS dan limbah cair dari sisa zat pembuatan larutan biasanya ditampung dan dikirim limbah B3. Oleh sebab itu perlunya ada pemanfaatan limbah biomassa untuk dijadikan karbon aktif.

Beberapa penelitian mengenai pembuatan karbon aktif dari berbagai bahan dengan aktivator kimia telah dilakukan di beberapa daerah lain dimana variabel yang digunakan beraneka ragam. Prameidia (2013) melakukan penelitian tentang pengaruh konsentrasi aktivator H2SO4 terhadap daya serap karbon aktif dari cangkang kelapa sawit pada konsentrasi 1, 2, $3 \mathrm{M}$ dengan ukuran partikel 60, 170, dan 200 mesh. Kondisi terbaik didapat pada konsentrasi 3 M dengan ukuran partikel 200 mesh menghasilkan kadar air 2,69 \%; kadar abu 1,85\%; dan daya serap terhadap iodin sebesar 888,370 mg/g. Noer Dkk (2014) didalam penelitiannya tentang pembuatan karbon aktif dari pelepah kelapa sawit dengan aktivator $\mathrm{H} 2 \mathrm{SO} 4$ sebagai adsorben yang menghasilkan kualitas karbon aktif yang terbaik diperoleh pada waktu karbonisasi dan aktivasi selama 60 menit dengan penyusutan massa 67,8\%, kadar air 5,5\%, kadar abu 8\%, kadar karbon 50,23\%, hidrogen 3,38\%, oksigen 43,18\%, bilangan iodin $373 \mathrm{mg} / \mathrm{gr}$ dan rendemen 37\%. Dari penelitian tersebut, kadar air yang didapatkan masih diatas syarat karbon aktif berdasarkan Standart Industri Indonesia (SII No. 0258-79) yaitu sebesar 4,4\%, maka perlu dilakukan pengembangan dengan meninjau bahan baku, aktivator dan konsentrasi aktivator yang berbeda. Pemanfaatan karbon aktif dari limbah biomassa (tongkol jagung, serbuk kayu merbau) diaplikasikan pada limbah cair laboraturium dari sisa analisa AAS. Limbah cair Laboratorium PT. Geoservices Palembang yang dihasilkan dari kegiatan analisa AAS dikumpulkan dalam suatu wadah kemudian dilakukan pengecekkan $\mathrm{pH}$ dan analisa kandungan logam sebelum sebelum di buang ke lingkungan. Oleh karena itu pada penelitian ini akan dilakukan pengolahan limbah cair Laboratorium PT. Geoservices Palembang dengan kombinasi proses adsorpsi menggunakan limbah biomassa dari tongkol jagung dan serbuk kayu merbau gunamenurunkan parameter tersebut. Tujuan dari penelitian ini adalah untuk mengetahui nilai parameter ( $\mathrm{pH}$ dan kandungan logam $\mathrm{Fe}$ dari limbah cair AAS) pada limbah cair PT. Geoservices Palembang, serta mengetahui efektivitas penurunan kandungan Logam Fe pada limbah dengan pengolahan menggunakan karbon aktif dari pemanfaatan limbah biomassa tersebut.

Adapun tujuan penelitian ini adalah memanfaatkan karbon aktif dari limbah biomassa tongkol jagung dan serbuk kayu merbau untuk pengolahan limbah cair alat AAS dan mengetahui efektivitas penurunan kadar logam $\mathrm{Fe}$ dan $\mathrm{Ph}$ yang terdapat pada limbah dengan penambahan karbon aktif.

\section{TINJAUAN PUSTAKA}

Menurut Undang-Undang Republik Indonesia Nomor 23 Tahun 1997 tentang Pengelolaan Lingkungan Hidup, limbah adalah sisa suatu usaha dan/atau kegiatan. Limbah cair adalah limbah berupa cairan yang berasal dari hasil buangan bahan-bahan yang telah terpakai dari suatu proses produksi industri, domestik (rumah tangga), pertanian, serta laboratorium yang tercampur (tersuspensi) dan terlarut di dalam air. Limbah cair disebut juga sebagai pencemar air, karena komponen pencemaran air pada umumnya terdiri dari bahan buangan padat, bahan buangan organik dan bahan buangan anorganik. Menurut Peraturan Pemerintah Nomor 18 Tahun 1999 juncto Nomor 85/1999 mengatur tentang Pengelolaan Limbah Bahan Berbahaya dan Beracun, limbah kimia B-3 adalah limbah yang mengandung bahan berbahaya dan/atau beracun karena sifat dan/atau konsentrasinya dan/atau jumlahnya, baik secara langsung maupun tidak langsung dapat mencemarkan 
dan/atau merusakkan lingkungan hidup, dan/atau membahayakan lingkungan hidup, kesehatan, kelangsungan hidup manusia serta makhluk hidup lainnya

Limbah laboratorium berasal dari buangan hasil reaksi-reaksi berbagai larutan kimia berbahaya dalam suatu eksperimen. Larutan kimia tersebut diantaranya mengandung bahan-bahan kimia toksik dan logam-logam berat yang berbahaya bagi makhluk hidup dan lingkungan. Bahanbahan kimia merupakan bahan yang berbahaya dan memiliki resiko tinggi bila tercemar ke lingkungan, karena memiliki zat yang bersifat racun (toksik). Tidak hanya bahan-bahan kimia, akan tetapi dimiliki oleh logam-logam berat misalnya $\mathrm{Fe}, \mathrm{Hg}, \mathrm{Cr}$, dan lainnya sehingga aliran buangan limbah laboratorium akan membahayakan lingkungan dan makhluk hidup di sekitarnya bila tidak dilakukan pengolahan limbah terlebih dahulu Karakteristik limbah cair dibedakan dalam beberapa jenis, yaitu fisika, kimia, dan biologi. Hal tersebut sangat penting dalam studi pendahuluan dalam pengolahan limbah, diantaranya proses desain, metode kerja, manajemen pengumpulan, pengelolaan, dan penimbunan air limbah. Sifat fisika, kimia, dan biologi air limbah sangat tergantung pada sumber kegiatan penghasil air limbah tersebut, apakah itu masyarakat, industri, atau komoditi lain. Karakteristik fisika, meliputi : temperatur (suhu), warna, bau, kekeruhan, padatan total, dan padatan tersuspensi. Karakteristik kimia, salah satunya ialah COD. Karakteristik biologi air limbah berhubungan dengan organisme-organisme dan/atau mikroorganisme dan bahan nutrien lainnya yang berperan untuk mengkonversi bahan organik menjadi bentuk yang lebih sederhana.

Pengolahan limbah dapat dilakukan dengan cara fisika, kimia, dan biologi atau gabungan ketiga sistem pengolahan tersebut. Berdasarkan tingkat pengolahan, maka sistem pengolahan limbah diklasifikasikan menjadi : pra pengolahan, pengolahan primer, pengolahan sekunder, dan pengolahan tersier. Adsorben ialah zat yang melakukan penyerapan terhadap zat lain (baik padat, cairan, maupun gas) pada proses adsorpsi. Umumnya adsorben bersifat spesifik, hanya menyerap zat tertentu. Dalam memilih jenis adsorben pada proses adsorpsi, disesuaikan dengan sifat dan keadaan zat yang akan diadsorpsi. Semakinkecil pori-pori adsorben, mengakibatkan luas permukaan semakin besar. Dengan demikian kecepatan adsorpsi bertambah. Adsorben yang paling banyak dipakai untuk menyerap zatzat dalam larutan adalah arang (karbon aktif). Tiap partikel adsorben dikelilingi oleh molekul yang diserap karena terjadi interaksi tarik menarik. Karbon aktif banyak dipakai di industri untuk menghilangkan zat-zat warna dalam larutan. Penyerapan bersifat selektif, yang diserap hanya zat terlarut atau pelarut (Brady, 1999). Arang aktif adalah senyawa berbahan dasar karbon yang telah diolah sehingga memiliki porositas tinggi dan luas permukaan besar. Dua sifat ini menyebabkan arang aktif dapat digunakan sebagai adsorben yang efektif untuk berbagai senyawa organik pada pengolahan air limbah. Berbagai macam sifat permukaan arang aktif juga dapat diproduksi dalam rangka memenuhi persyaratan untuk penggunaan tertentu. Pasar terbesar produk arang aktif adalah untuk pengolahan air dan air limbah (Kirk \& Othmer 1964).

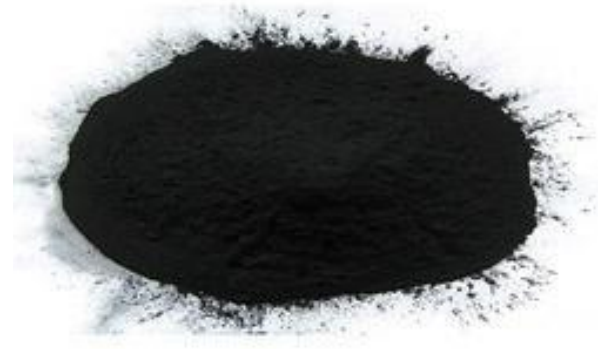

Gambar 1. Karbon Aktif

Proses karbonisasi merupakan salah satu tahap penting dalam pembuatan arang aktif. Pada umumnya proses ini dilakukan pada suhu $400-600{ }^{\circ} \mathrm{C}$ (Smisek \& Cerny 1970). Produk karbon aktif 
yang telah dihasilkan melalui tahapan karbonisasi dan aktivasi, baik aktivasi kimia maupun aktivasi fisika harus memenuhi Standar Nasional Indonesia (SNI) yang telahditentukan.

Tabel 1. Analisis Mutu Karbon Aktif

\begin{tabular}{|c|c|}
\hline Parameter Mutu (\%) & Syarat Mutu Karbon Aktif \\
\hline Kadar Air & $15 \%$ \\
Kadar Abu & $10 \%$ \\
Kadar Zat Mudah Menguap & $15 \%$ \\
Kadar Karbon Terikat & $65 \%$ \\
Penyerapan Iodium & $200 \mathrm{mg} / \mathrm{g}$ \\
\hline
\end{tabular}

Sumber: SNI 06-3730-1995

Dalam pembuatan karbon aktif, terdapat syarat mutu atau kriteria mutu yang harus dimiliki oleh karbon aktif yang dibuat. Syarat mutu dalam pembuatan karbon aktif ini telah ditetapkan oleh Standar Industri Indonesia (SII). Syarat mutu karbon aktif menurut Standar Industri Indonesia (SII) dapat dilihat di Tabel 2.

Tabel 2. Syarat Mutu Karbon Aktif

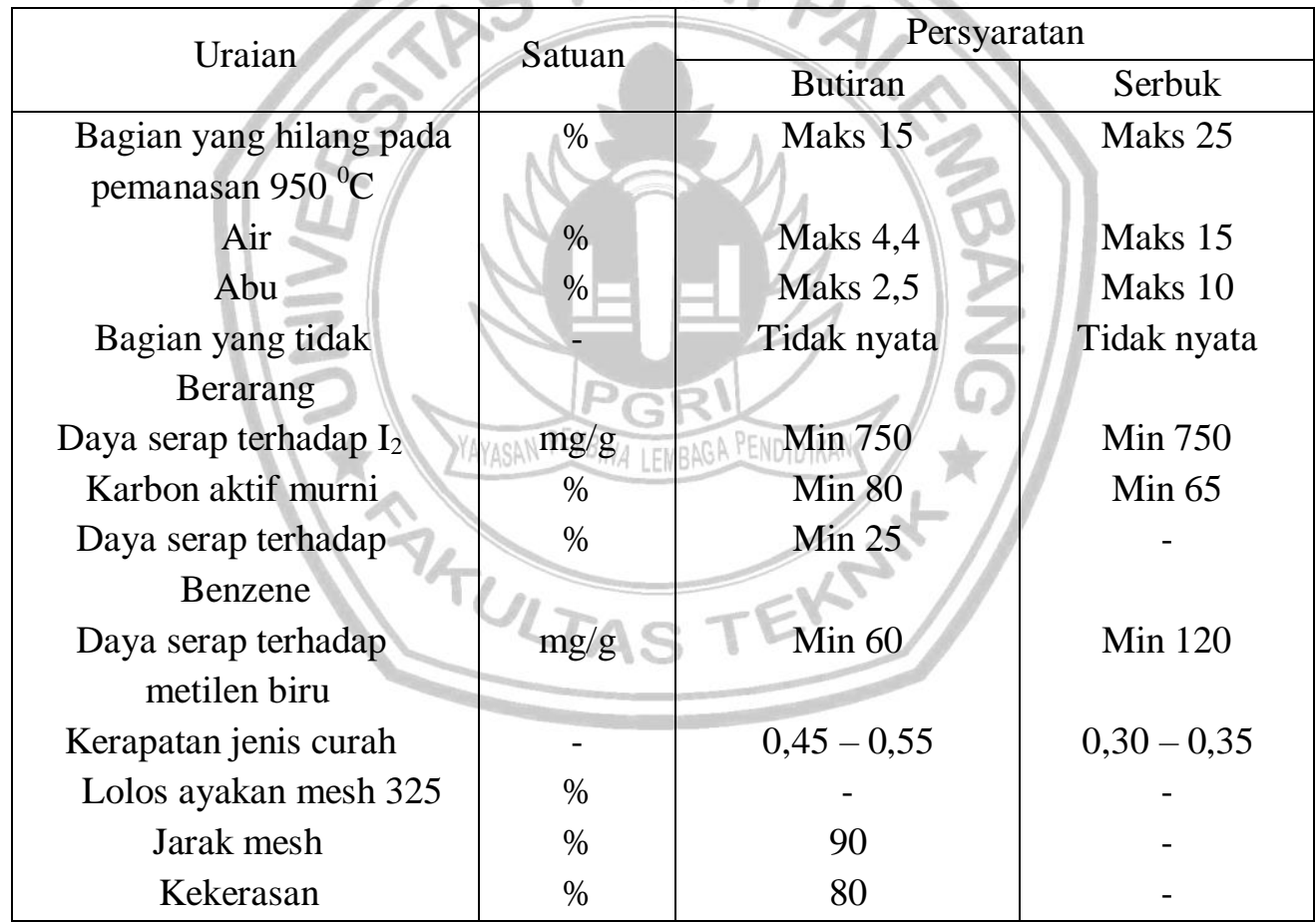

Sumber : Standar Industri Indonesia (SII No. 0258-79)

Karbonisasi atau pengarangan adalah proses mengubah bahan menjadi karbon berwarna hitam melalui pembakaran dalam ruang tertutup dengan udara yang terbatas atau seminimal mungkin. Proses pembakaran dikatakan sempurna jika hasil pembakaran berupa abu dan seluruhenergi di dalam bahanorganikdibebaskan ke lingkungan dengan perlahan. Secara ringkas proses karbonisasi dapat ditampilkan dalam bagan (Kurniawan dan Marsono 2008). Faktor-faktor yang mempengaruhi proses karbonasi (Kurniati, E; 2008) :

1. Waktu karbonisasi

Bila waktu karbonisasi diperpanjang maka reaksi pirolisis semakin sempurna sehingga hasil arang semakin turun tetapi cairan dan gas makin meningkat.

2. Suhu karbonisasi

Suhu karbonisasi yang berpengaruh terhadap hasil arang karena semakin tinggi suhu, arang yang 
diperoleh makin berkurang tapi hasil cairan dan gas semakin meningkat.Hal ini disebabkan oleh makin banyaknya zat-zat terurai dan yang teruapkan.

Aktivasi adalah suatu perlakuan terhadap arang yang bertujuan untuk memperbesar pori yaitu dengan cara memecahkan ikatan hidrokarbon atau mengoksidasi molekul-molekul permukaan sehingga arang mengalami perubahan sifat, baik fisika maupun kimia, yaitu luas permukaannya bertambah besar dan berpengaruh terhadap daya adsorpsi (Sembiring, 2003). Metoda aktivasi yang umum digunakan dalam pembuatan arang aktif adalah Aktivasi fisika merupakan proses pemutusan rantai karbon dari senyawa organik dengan bantuan panas, uap dan CO2 (Sembiring, 2003). Metode aktivasi secara fisika antara lain dengan menggunakan uap air, gas karbon dioksida, oksigen dan nitrogen. Gas-gas tersebut berfungsi untuk mengembangkan struktur rongga yang ada pada arang sehingga memperluas permukaannya, menghilangkan konstituen yang mudah menguap dan membuang produksi tar atau hidrokarbon pengotor pada arang. (Rumidatul, Alfi 2006). Selanjutnya aktivasi secara kimia biasanya menggunakan bahan-bahan pengaktif seperti garam Kalsium Klorida $\left(\mathrm{CaCl}_{2}\right)$, Magnesium Klorida $\left(\mathrm{MgCl}_{2}\right)$, Seng Klorida $\left(\mathrm{ZnCl}_{2}\right)$, Natrium Hidroksida $(\mathrm{NaOH})$, Kalium Hidroksida $(\mathrm{KOH})$, Natrium Karbonat $\left(\mathrm{Na}_{2} \mathrm{CO}_{3}\right)$ dan Natrium Klorida $(\mathrm{NaCl})$, AsamPhospat $\left(\mathrm{H}_{3} \mathrm{PO}_{4}\right)$, Asam Nitrat $\left(\mathrm{HNO}_{3}\right)$, Hidrogen Peroxida $\left(\mathrm{H}_{2} \mathrm{O}_{2}\right)$, Kalium Permanganat $\left(\mathrm{KMnO}_{4}\right)$, Ammonia Sulfat $\left(\mathrm{NH}_{4}\right)_{2} \mathrm{SO}_{4}$, Asam Klorida( HCl). Siti Salamah (2008). Pembayun, dkk (2013), menyebutkan bahwa dengan meningkatnya konsentrasi aktivator maka semakin banyak pori yang terbentuk sehingga daya serap iodin karbon aktif jugameningkat.

Siti Salamah (2008), menyebutkan bahwa semakin besar konsentrasi zat aktivasi maka daya serap karbon yang dihasilkan semakin besar, tetapi pada penggunaan konsentrasi yang terlalu tinggi akan mengdegradasi atau merusak selulosa yang mengakibatkan daya serap karbon aktif menurun. Daya serap karbon aktif semakin kuat bersamaan dengan meningkatnya konsentrasi dari aktivator yang ditambahkan. Hal ini memberikan pengaruh yang kuat untuk mengikat senyawa-senyawa tar keluar melewati mikro pori-pori dari karbon aktif sehingga permukaan/dari karbon aktif tersebut semakin lebar atau luas yang mengakibatkan semakin besar pula daya/serap karbon aktif tersebut. (Tutik M dan Faizah H,2001).

Penentuan sifat-sifat karbon aktif yang diperoleh melalui karbonisasi dan aktivasi, maka perlu dilakukan karakterisasi. Karakterisasi dalam penelitian ini meliputi,

1. Kadar Air

Penentuan kadar air bertujuan untuk mengetahui sifat higroskopis arang aktif, dimana karbon aktif mempunyai sifat afinitas yang besar terhadap air. Berdasarkan SNI No. 06-3730-1995, karbon aktif yang baik mempunyai kadar air maksimal 15\% (Jankowska, et al: 1991).

2. Kadar Zat Terbang

Prinsip dalam penentuan kadar zat terbang adalah sampel dari air menguap pada suhu $100^{\circ} \mathrm{C}$ sehingga tercapai berat konstan selama \pm 4 jam (kadar air) diambil sebangak 1 gram lalu dipanaskan dalam furnace pada suhu $900^{\circ} \mathrm{c}$ selama 7 menit. Berdasarkan SNI No. 06-3730-1995, karbon aktif yang baik mempunyai kadar abu maksimal15\%.

3. Kadar Abu

Penentuan kadar abu biasanya pada temperatur $600-900^{\circ} \mathrm{C}$ selama 3-16 jam. Berdasarkan SNI No. 06-3730-1995, karbon aktif yang baik mempunyai kadar abu maksimal 10\% (Jankowska, et al: 1991).

4. Penentuan KarbonTerikat

Karbon dalam arang adalah zat yang terdapat pada fraksi padat hasil pirolisis selain abu (zat organik) dan zat-zat yang masih terdapat pori-pori arang. Prosedur pengujian dan perhitungan kadar karbon mengacu pada SNI 06-3730-1995. 


\section{Daya SerapIodine}

Angka iodin didefinisikan sebagai jumlah miligram iodin yang diadsorpsi oleh satu gram karbon aktif.. Jankowska, et al: 1991). Berdasarkan Standar Nasional Indonesia No. 06-3730-1995, karbon aktif yang baik mampu menyerap iodin minimal $200 \mathrm{mg} / \mathrm{L}$.

Tabel 3.Persyaratan Arang Aktif menurut Standart Industri Indonesia (SII No. 0258-79) yang dikeluarkan Departmen Perindustrian.

\begin{tabular}{|c|c|c|c|}
\hline No. & Parameter & Satuan & Kadar \\
\hline 1 & Bagian yang hilang pada suhu $950^{\circ} \mathrm{C}$ & $\%$ & Max 15 \\
\hline 2 & Air & $\%$ & Max 10 \\
\hline 3 & Abu & $\%$ & Max 2.5 \\
\hline 4 & Daya serap terhadap $\mathrm{I}_{2}$ & $\%$ & Min 20 \\
\hline
\end{tabular}

(Sumber: BPKI, 2009)

Merbau adalah sejenis pohon penghasil kayu keras berkualitas tinggi anggota suku fabaceae. Karena kekerasannya, di wilaya maluku dan papua kayu ini dinamai kayu besi. Pohon berperawakan sedang hingga besar, dapat mencapai tinggi $50 \mathrm{~m}$, dengan batang bebas cabang sekitar $20 \mathrm{~m}$ dan gemang hingga $160 \mathrm{~cm}$. Dengan banir ( akar papan ) yang tinggi dan tebal. Pepagan berwarna abu-abu terang, halus dengan bintil bintil kecil lentisel,mengelupas serupa sisik sisik bulat. Daun majemuk dengan 2 pasang anak daun. Bunga bunga terkumpul dalam karangan di ujung, panjang hingga $10 \mathrm{~cm}$, berambut halus, mahkota berwarna putih,yang berubah menjadimerah. Kayu teras berwarna kelabu coklat atau kuning coklat sampai coklat merah cerah atau hampir hitam. Merbau memiliki tekstur kayu yang kasar dan merata, dengan arah serat yang kebanyakan lurus. Kayu yang telah diolah memiliki permukaan yang licin dan mengkilap indah. Kayu merbau termasuk tidak sulit di gergaji, dapat diserut dengan mesin sampai halus, diamplas dan di pelitur, namun kurang baik untuk di bubut. Kayu ini juga biasanya pecah apabila dipaku,dan dapat menimbulkan noda hitam apabila berhubungan dengan besi atau terkenaair.

Tongkol jagung adalah bagian dalam organ betina tempat bulir duduk menempel. Istilah ini juga dipakai untuk menyebut seluruh bagian jagung betina (buah jagung). Tongkol terbungkus oleh kelobot (kulit buah jagung). Secara morfologi, tongkol jagung adalah tangkai utama malai yang termodifikasi, Malai organ jantan pada jagung dapat memunculkan bulir pada kondisi tertentu. Tongkol jagung muda, disebut juga babycorn, dapat dimakan dan dijadikan sayuran. Tongkol yang tua ringan namun kuat, dan menjadi sumber furfural, sejenis monosakarida dengan lima atom karbon. Tongkol jagung tersusun atas senyawa kompleks lignin, hemiselulose dan selulose. Masing-masing merupakan senyawa-senyawa yang potensial dapat dikonversi menjadi senyawa lain secara biologi (Suprapto dan Rasyid,2002). Sebuah perusahaan di Iowa, AS berhasil memanfaatkan tongkol jagung sebagai berbagai produk yang ramah lingkungan. Tongkol memiliki sifat-sifat seperti salah satu bagiannya keras dan sebagian bersifat menyerap (absorbent), juga sifat-sifat yang merupakan gabungan beberapa sifat, seperti: tidak terjadi reaksi kimia bila dicampur dengan zat kimia lain (inert), dapat terurai secara alami dan ringan sehingga tongkol jagung berupakan bahan ideal campuran pakan, bahan campuran insektisida dan pupuk. Serta dapat digunakan sebagai alas hewan peliharaan karena alami, bersih dan dapat mengurangi bau tidak sedap (www.ciras.iastate.edu/iof). Penggunaan tongkol jagung untuk keperluan bahan bakar sekitar 90\% sedangkan limbah batang dan daun sekitar $30 \%$ dari potensi yang ada. Tongkol jagung memiliki kandungan karbon yang tinggi. Hasil penelitian menunjukkan bahwa untuk mengeringkan 6 ton jagung dari kadar air 32.5\% sampai $13.7 \%$ bb selama 7 jam diperlukan sekitar $30 \mathrm{~kg}$ tongkol jagung kering per jam (Alkuino,2000).

Toksisitas logam adalah terjadinya keracunan dalam tubuh manusia yang diakibatkan oleh bahan berbahaya yang mengandung logam beracun. Logam Fememiliki toksisitas, yaitu iritasi kulit, 
gangguan pencernaan, dan gangguan pernapasan. Sedangkan, logam Mn dapat merusak paru-paru dan otak. Logam Cr memiliki toksisitas, yaitu iritasi kulit dan gangguan pencernaan. Salah satu metode analisis unsur yang paling akurat dan sering digunakan dalam analisis unsur logam adalah Spektrofotometer Serapan Atom atau Atomic Absorption Spectrophotometer (AAS). Prinsip dari metode AAS adalah absorbsi cahaya oleh atom berdasarkan jumlah radiasi yang diabsorbsi atom-atom dalam fase uap dari keadaan dasar ke keadaan tereksitasi . Dengan demikian, alat ini dapat digunakan untuk mengidentifikasi kandungan logam dalam suatu sampel. Metode ini sangat tepat untuk analisis zat pada konsentrasi rendah (Sunardi,2010).

Proses pengolahan air limbah yang dilakukan dalam skala industri, meliputi proses kimia dan fisika. Proses kimia dengan menambahkan bahan kimia pembentuk endapan (koagulan/ flokulan), pembunuh kuman (desinfektan) dan penetralan. Sedangkan, proses fisika meliputi penyaringan (filtrasi) yang terdiri dari penyaringan dengan penyaring pasir cepat, penyaring metal dan penyaring karbon aktif. Hal tersebut ditunjukkan pada Gambar2.

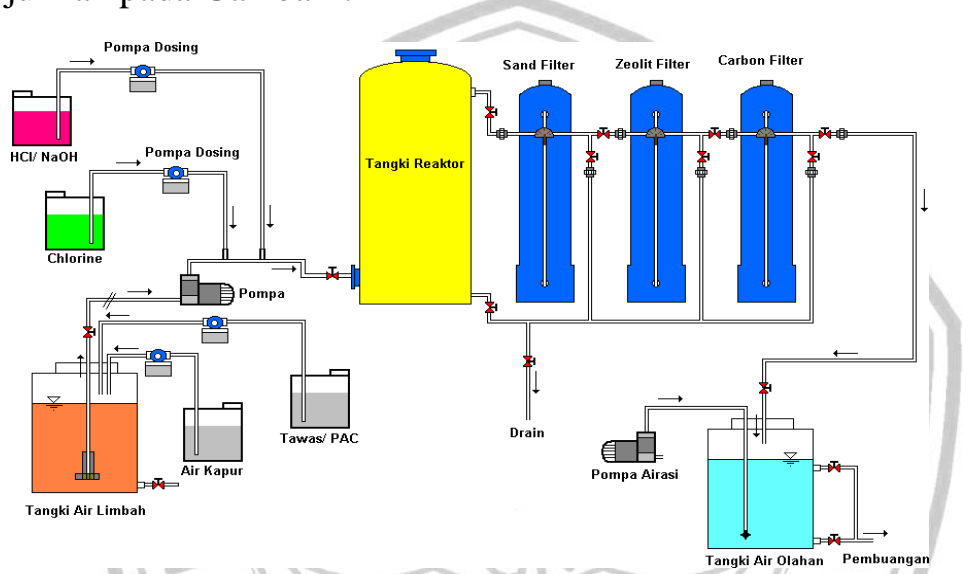

Gambar 2.Sistem Pengolahan Air Limbah Laboratorium

Keberhasilan proses pengolahan air limbah ini sangat bergantung kepada kodisi air limbah, kapasitas system dan kecepatan aliran air limbah (Sunardi, 2010). Pada penelitian ini, dilakukan proses pengolahan limbah cair laboratorium kimia dalam penurunan kadar organik dan logam berat $\mathrm{Fe}, \mathrm{Mn}, \mathrm{Cr}$ dengan metode koagulasi dan adsorpsi. Teknik pengolahan limbah yang dilakukan pada penelitian ini menggunakan bahan koagulan tawas, PAC, trimer 3626, dan trimer 6784. Pada proses adsorpsi, digunakan adsorben zeolit dan karbon aktif untuk membandingkan keefektifan kedua adsorben tersebut terhadap sampel limbah cair laboratorium kimia. Penelitian ini merupakan teknik pengolahanlimbahsederhana, yaitu dalam skala laboratorium sehingga ada beberapa penambahan bahan, seperti klorin yang tidak dilakukan pada penelitian ini serta menggunakan alat yang sederhana. Namun, prosesnya disesuaikan dengan pengolahan limbah yang sebenarnya untuk memperoleh hasil limbah olahan yang efektif, ramah lingkungan, biaya yang terjangkau, dan sesuai dengan kadar baku mutu air limbah.

\section{METODE PENELITIAN}

\section{Bahan}

Serbuk Kayu Merbau,Tongkol Jagung, Asam Sulfat sebagai activator, Limbah AAS, Kertas Saring Whatman,Aquadest

\section{Alat}

Furnace, Oven, Gelas kimia 1000ml,Gelas kimia 500ml,Gelas ukur100ml,Labu Ukur 500ml,Neraca analitik, Seperangkat alatAAS,Desikator,Pipet Ukur 10ml,Baskom kecil,Ayakan 60 mesh,Cawan Porselen.Hot Plate,cawan porcelain,pH meter,Erlemeyer $250 \mathrm{ml}$, corong Bunche 
Perlakuan dan RancanganPercobaan

PerlakuanPenelitian

1. Preparasi serbuk kayu merbau dan tongkoljagung

2. Proses Karbonisasi dan ProsesAktivasi

3. Uji Kualitas Karbon Aktif sebelum dilakukan aktivasi dengan perbadingan kulitas SNI06-37301995

4. Analisa Pengolahan limbah setelah penambahan karbonaktif.

Rancangan Penelitian

Penelitian ini dilakukan untuk mengetahui keadaan optimal dari pengaruh variasi penambahan aktivator dimana aktivator yang digunakan adalah asam sulfat dan variasi suhu pemanasan (pengkarbonan). Pengaplikasian karbon aktif di gunakan untuk mengetahui penurunan kandungan logam yang ada pada limbah AAS dan $\mathrm{pH}$ sebelum dan sesudah dilakukan pengolahan dengan karbon aktif.

\section{HASIL DAN PEMBAHASAN}

Dari hasil penelitian yang telah dilakukan untuk mendapatkan karbon aktif beberapa proses yaitu proses pembuatan karbon aktif yang dilakukan dengan karbonisasi pada suhu 200, 250, 300, 350, $400{ }^{\circ} \mathrm{C}$ selama 1 jam dan proses aktivasi dengan aktivator larutan $\mathrm{H}_{2} \mathrm{SO}_{4}$ dengan variasi konsentrasi 0,5 $\mathrm{M}, 2,0 \mathrm{M}, 3,0 \mathrm{M}$ selama 24 jam. Tujuan dari variasi konsentrasi aktivator ini untuk mendapatkan karbon aktif yang sesuai dengan Standar Nasional Indonesia (SNI). Karbon aktif yang didapatkan diuji kualitasnya yang meliputi; kadar air, kadar abu, kadar zat terbang. Setelah SNI dari karbon aktif terpenuhi maka karbon aktif akan di aplikasikan pada limbah AAS tujuannya untuk menunrunkan kadar logam yang terdapat pada limbahAAS.

\section{AnalisaProduk}

\section{Penentuan Kadar Air}

Penentuan kadar air pada karbon aktif bertujuan unutk mengetahui sifat higroskopis dari karbon aktif. Higroskopis adalah kemampuan suatu zat untuk menyerap molekul air dari lingkungannya baik absorpsi maupun adsorpsi. Semakin banyak pori-pori karbon aktif tersebut, maka akan meningkatkan sifat higroskopis (Hendaway, 2003).

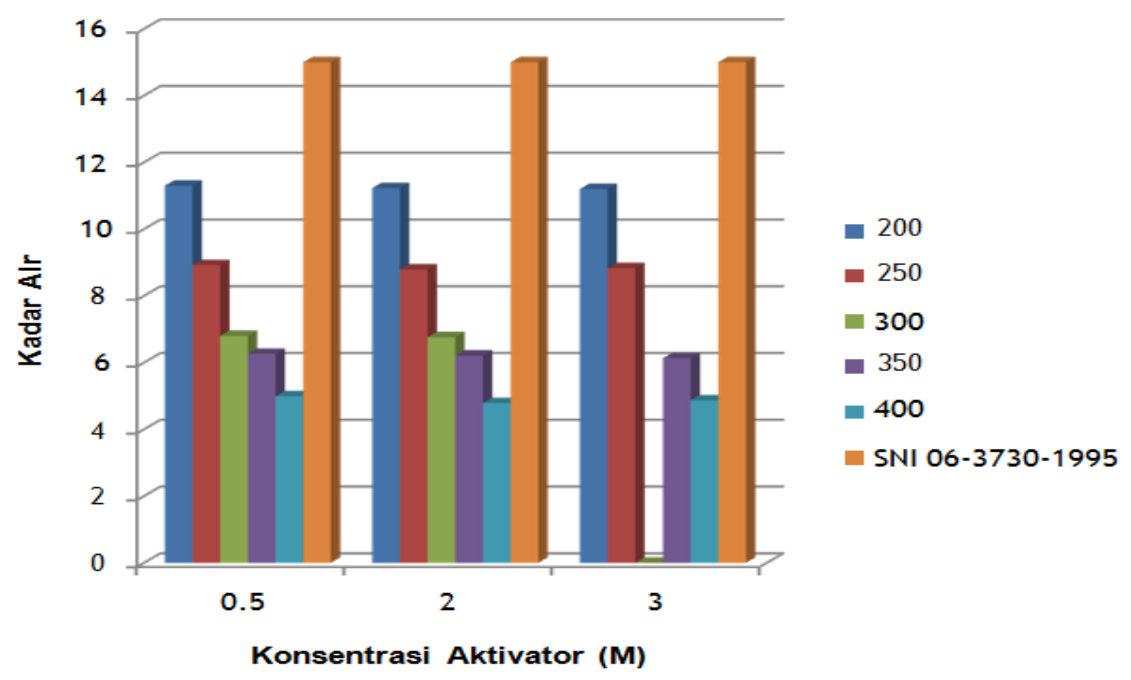

Gambar 5. Grafik Hubungan Antara Konsentrasi Aktivator Terhadap Kadar Air 


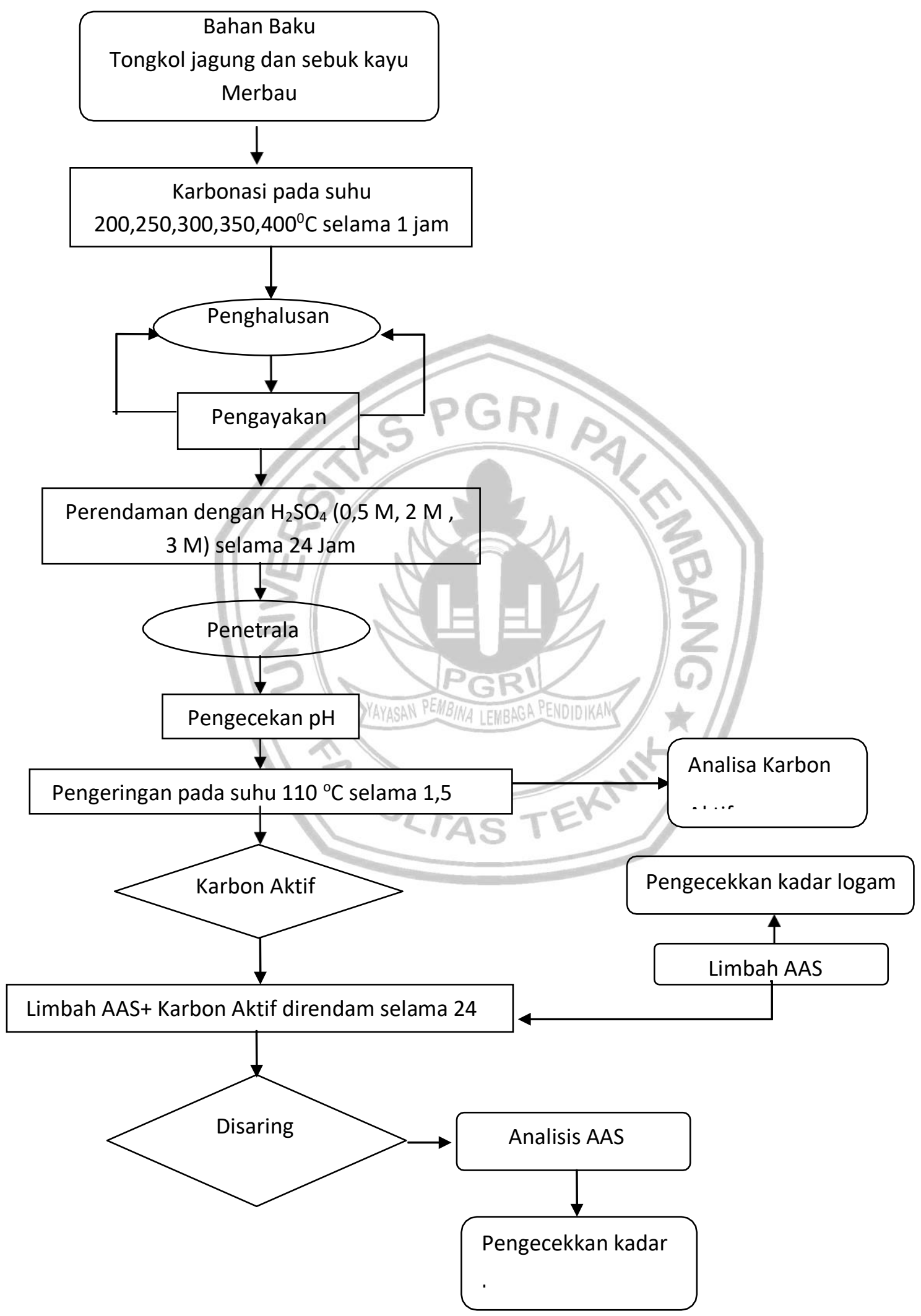

Gambar 3. Diagram Alir Proses Pembuatan karbon aktif dan analisa 
Gambar 5.terlihat semakin tinggi suhu pemanasan (karbonisasi dan semakin tinggi konsentrasi activator) maka kadar air semakin kecil. Hal ini sama dengan pernyataan Sani (2011), semakin tinggi konsentrasi aktivator, maka kadar air semakin kecil. Hal ini disebabkan oleh struktur karbon aktif yang tersusun dari6 atom $\mathrm{C}$ pada setiap sudut heksagonal, yang memungkinkan butir-butir air terperangkap didalamnya. Konsentrasi aktivator juga memberikan pengaruh pada proses aktivasi, yaitu semakin tinggi konsentrasi aktivator, semakin besar pula pengaruhnya untuk mengikat senyawa-senyawa tar keluar melewati rongga atau pori-pori dari karbon aktif, sehingga volume pori semakin luas. Disamping itu, aktivator dapat mendegradasi/mendehidrasi molekul organik selama proses karbonisasi (Kirk-Othmer, 1992).

\section{Penentuan Kadar Abu}

Penentuan kadar abu dilakukan untuk menganalisa kadar abu pada karbon aktif yang dihasilkan. Kadar abu yang besar akan mempengaruhi kualitas karbon aktif sebagai adsorber.

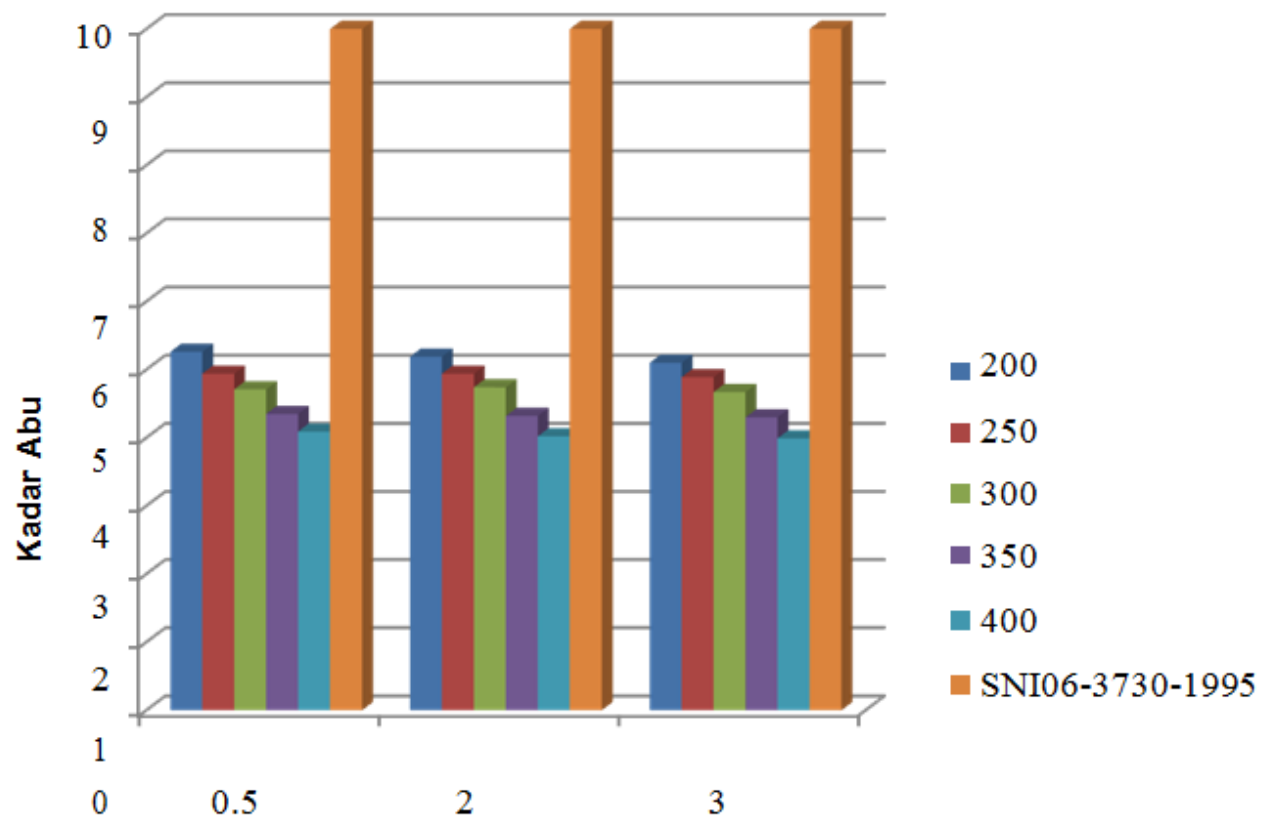

Konstrasi Aktivator (M)

Gambar 6. Grafik Hubungan Antara Konsentrasi Aktivator Terhadap Kadar Abu

Gambar 6, terlihat bahwa semakin besar konsentrasi aktivator maka kadar abu semakin tinggi. Ini disebabkan karena masih adanya kandungan mineral-mineral logam yang masih menempel dipermukaan karbon aktif (Dwi,2013). Karbon aktif yang mempunyai kadar abu yang terbaik ada pada konsentrasi $\mathrm{H}_{2} \mathrm{SO}_{4} 3 \mathrm{M}$ yaitu sebesar 3,99\%. Jika dibandingkan dengan penelitian yang dilakukan oleh Valeni Agustia (2014) yang membuat karbon aktif dari cangkang sawit dengan aktivator $\mathrm{Na}_{2} \mathrm{CO}_{3}$ memiliki kadar abu 1,20 - 1,30 \% dan juga, Siti Jamiatun (2014), kadar abu karbon aktif dari tempurung kelapa dengan aktivator 5-25 $\% \mathrm{ZnCl}_{2}$ berkisar pada $1,30-7,80 \%$, maka kadar abu cangkang dengan aktivator $\mathrm{HCl} 5 \%$ mempunyai nilai yang kecil jika dibandingkan dengan peneliti yang sebelumnya dengan menggunakan aktivator yang berbeda. Abu yang dihasilkan berupa oksidaoksida logam yang terdiri dari mineral yang tidak menguap pada proses karbonisasi (Dwi, 2013).

Kadar abu yang tinggi akan mempengaruhi proses adsorpsi, karena akibat adanya mineralmineral logam yang menutupi pusat aktif dari karbon akitf dalam menyerap larutan maupun gas. Kadar abu dari serbuk kayu merbau dan tongkol jagung berkisar antara 3,99-5,26\%. Berdasarkan SNI 06- 
3730-1995, syarat kadar abu yang diperbolehkan pada karbon aktif adalah maksimal 10\%. Karbon aktif yang memiliki kadar abu rendah diantara kadar abu semuanya adalah karbon aktif dari serbuk kayu merbau dan tongkol jagung dengan aktivasi asamH ${ }_{2} \mathrm{SO}_{4}$.

2. Penentuan Zat Terbang (Volatile Matter)

Kadar zat terbang menunjukkan zat-zat yang mudah menguap yang hilang pada pemanasan $900^{\circ} \mathrm{C}$. Gambar 7, dapat terlihat bahwa kadar zat terbang karbon aktif yang dihasilkan dari serbuk kayu merbau dan tongkol jagung tidak memenuhi syarat standar SNI. Pada data diatas terlihat jelas bahwa pencampuran karbon aktif serbuk kayu merbau dan tongkol jagung memberikan pengaruh yang dilakukan oleh Azmin AMin 2016, didapatkan bahwa nilai zat terbang yang diperoleh yaitu

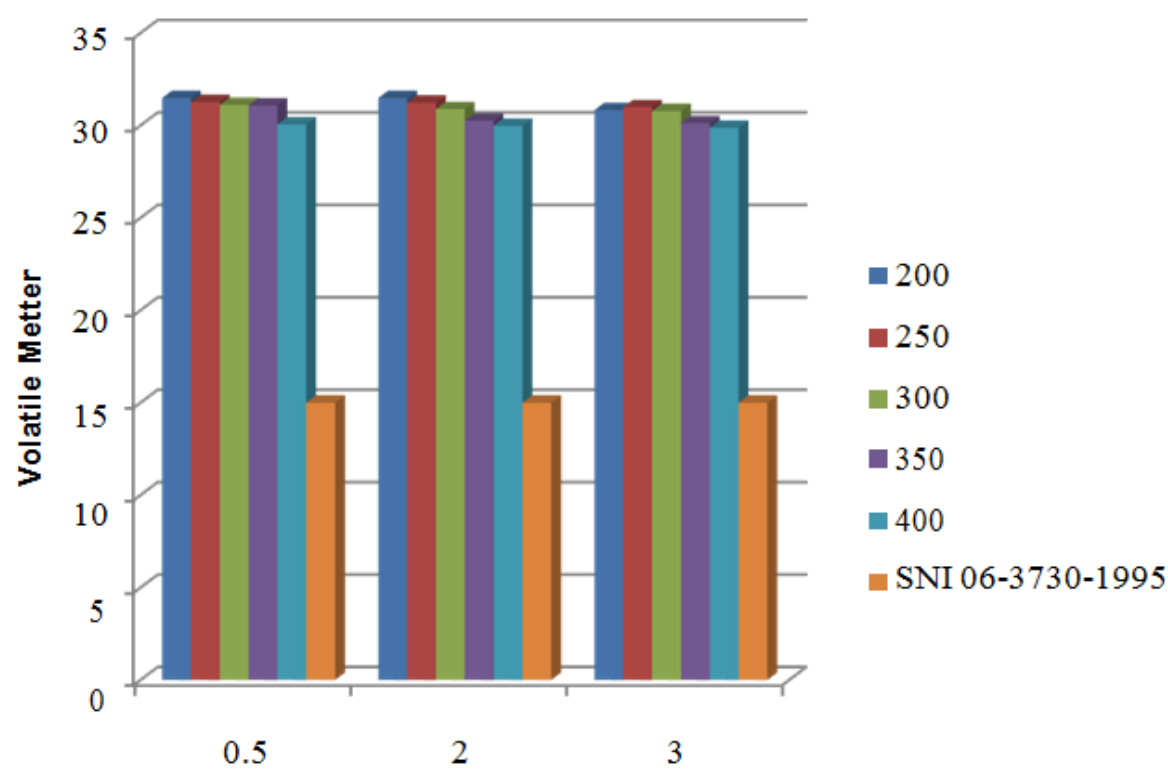

Konsentrasi Aktivator

Gambar 7. Grafik Hubungan Antara Konsentrasi Aktivator Terhadap Volatile Matter

$35,80 \%$, nilai terebut sangat rendah dibandingkan dengan hasil yang diperoleh dari karbon aktif hal ini disebabkan karena kandungan zat terbang pada tongkol jagung cukup tinggi yaitu $80 \%$,serta kandungan zat-zat lain yang terdapat didalam batubara lignit maupun serbuk kayu merbau.

Zat-zat tersebut berupa senyawa sulfur, nitrogen dan senyawa volatile lainya yang masih terdapat didalam pori-pori karbon aktif (Dwi, 2013). Hal tersebut dapat mengurangi daya serapnya terhadap gas atau larutan. Menurut SNI 06-3730-1995, syarat mutu karbon aktif harus memenuhi standar zat terbang maksimal 15\%. Sedangkan karbon aktif yang dihasilkan, seluruhnya telah memenuhi syarat mutu karbon aktif Standar Nasional Indonesia (SNI) 06-3730- 1995.

3. Kadar Karbon Tertambat (Fixed Carbon)

Kadar karbon tertambat adalah jumlah fraksi karbon terikat di dalam karbon aktif selain fraksi air, zat menguap, dan abu (Fauziah, 2009). Menurut Fauziah (2009), tinggi rendahnya kadar karbon tertambat dipengaruhi oleh kadar air, abu, zat terbang, dan senyawa hidrokarbon yang masih menempel pada permukaan arang yang juga dipengaruhi oleh kandungan selulosa dan lignin bahan baku yang dapat dikonversi menjadi atom carbon(C). 
Tabel 4. Hasil Analisa untuk Kadar Karbon Tertambat Karbon Aktif dari Serbuk Kayu Merbau dan Tongkol Jagung

\begin{tabular}{|c|c|c|c|c|c|}
\hline $\begin{array}{c}\text { Temperatur } \\
\left({ }^{\circ} \mathrm{C}\right)\end{array}$ & $\begin{array}{c}\text { Konsentrasi } \\
\text { (M) }\end{array}$ & $\begin{array}{c}\text { Kadar Air } \\
(\%)\end{array}$ & $\begin{array}{c}\text { Kadar Abu } \\
(\%)\end{array}$ & $\begin{array}{l}\mathrm{VM} \\
(\%)\end{array}$ & $\begin{array}{r}\text { Fixed } \\
\text { carbon } \\
(\%)\end{array}$ \\
\hline \multirow{3}{*}{$\begin{array}{c}20 \\
0\end{array}$} & 0,5 & 11,30 & 5,26 & 31,48 & 51,96 \\
\hline & 2,0 & 11,23 & 5,19 & 31,48 & 52,10 \\
\hline & 3,0 & 11,20 & 5,10 & 30,83 & 52,87 \\
\hline \multirow{3}{*}{$\begin{array}{c}25 \\
0\end{array}$} & 0,5 & 8,92 & 4,94 & 31,27 & 54,87 \\
\hline & 2,0 & 8,79 & 4,94 & 31,23 & 55,04 \\
\hline & 3,0 & 8,83 & 4,89 & 30,99 & 55,29 \\
\hline \multirow{3}{*}{$\begin{array}{c}30 \\
0\end{array}$} & 0,5 & 6,80 & 4,71 & 31,11 & 57,38 \\
\hline & 2,0 & 6,76 & 4,74 & 30,88 & 57,62 \\
\hline & 3,0 & 6,75 & 4,67 & 30,78 & 57,80 \\
\hline \multirow{3}{*}{$\begin{array}{c}35 \\
0\end{array}$} & 0,5 & 6,26 & 4,35 & 31,08 & 58,31 \\
\hline & 20 & 6,21 & 4,32 & 30,25 & 59,22 \\
\hline & & & 4,30 & 3012 & 59,45 \\
\hline \multirow{3}{*}{$\begin{array}{c}40 \\
0\end{array}$} & & 4,99 & 4,09 & 30,06 & 60,86 \\
\hline & 2,0 & 4,79 & 4,02 & 29,98 & 61,21 \\
\hline & 3,0 & 4,87 & 3,99 & 29,87 & 61,27 \\
\hline
\end{tabular}

Berdasarkan tabel 4. diatas, terlihat bahwa kadar karbon tertambat karbon aktif yang dihasilkan nilainya terus meningkat sering bertambahnya konsentrasi aktivator. Kandungan karbon tertambat yang kecil akan mempengaruhi daya serapnya karena senyawa organik yang masih menutupi permukaan karbon untuk proses adsorpsi.Menurut SNI 06-3730-1995, syarat mutu karbon tertambat pada karbon aktif belum memenuhi standar ialah minimal $65 \%$. Hal ini dikarenakan tingginya volatile metter yang terdapat pada karbon aktif dari serbuk kayu merbau dan tangkol jagung.

\section{Analisa Limbah Cair Limbah AAS \\ Analisa pH}

Penentuan $\mathrm{pH}$ dilakukan agar limbah cair AAS tidak mencemari lingkungan sebelum di buang ke lingkungan sekitar. Untuk itu perlu dilakukan pengolahan agar $\mathrm{pH}$ sebelum dibuang ke sistem perairan tidak mencemari lingkungan sekitar.

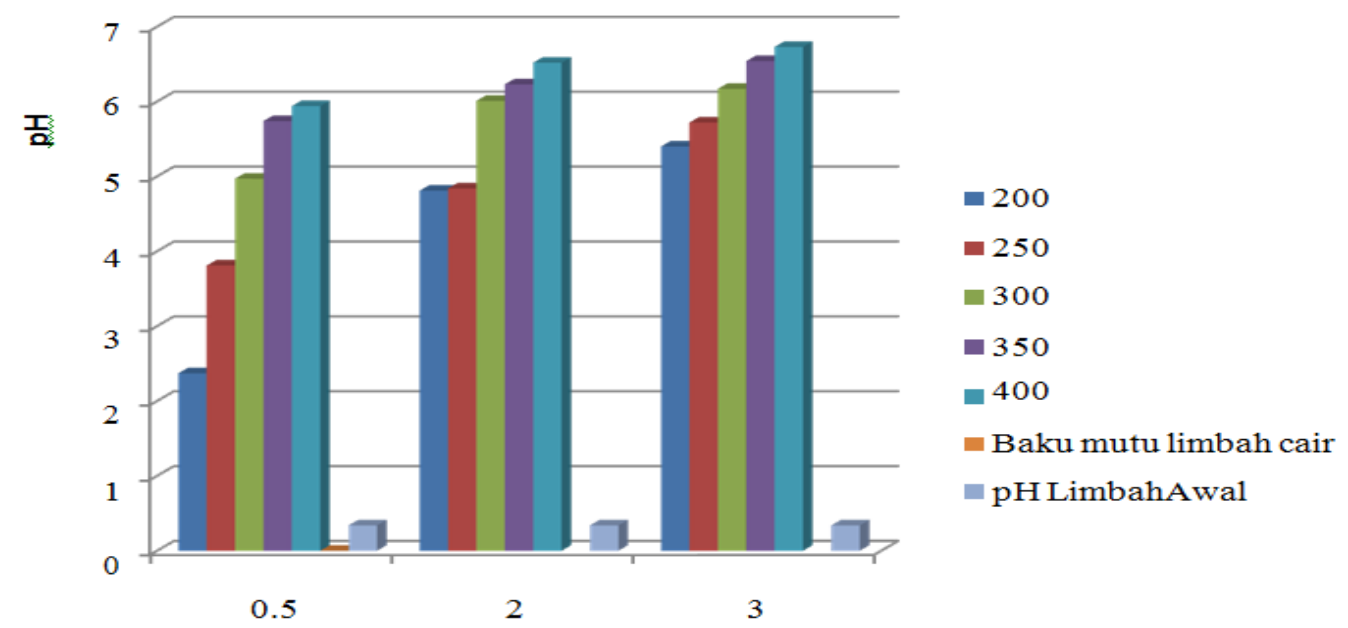

Konsentrasi Aktivator (M)

Gambar 8. Hubungan Antara konsentrasi aktivator dengan $\mathrm{pH}$ 
Gambar 8 dapat dilihat bahwa nilai pH yang dihasilkan dari pengolahan dengan menggunakan karbon aktif dari serbuk kayu merbau dan tongkol jagung terus meningkat mendekati $\mathrm{pH}$ netral $(7,00)$ seiring dengan semakin tingginya aktivator karbon aktif. Dari data untuk $\mathrm{pH}$ pada limbah awal yaitu 0,34 hal ini dikarenakan pada saat analisa AAS banyak menggunakan asam kuat seperti $\mathrm{HF}_{2} \mathrm{H}_{2} \mathrm{SO}_{4}$ dan HCl. Menurut Irmanto (2010), dimana pada saat karbon aktif telah mencapai kondisi optimum, maka daya serap cenderung menurun karena permukaan karbon telah jenuh oleh adsorbat. Jika dibandingkan dengan hasil penelitian yang dilakukan oleh Ratih Mandasari (2014), pH limbah cair kelapa sawit yang didapatkan setelah pengolahan secara flokulasi dan koagulasi dengan PAC mendekati netral $(6,64)$, dan penelitian Sylvizah Sinta Pratiwi (2014) dengan menggunakan karbon aktif dengan aktivator $\mathrm{H}_{3} \mathrm{PO}_{4}$ mendapatkan $\mathrm{pH}$ mendekati netral $(6,5)$. Dari berbagai variasi konsentrasi aktivator pada karbon aktif, terlihat untuk karbon aktif dengan konsentrasi aktivator karbonM $\mathrm{H}_{2} \mathrm{~S}$ aktif $3 \mathrm{O}_{4}$ memilikipH netral $(7,02)$ sehingga jika dibuang ke lingkungan tidak akan mencemari lingkungannya.

\section{Analisa $\mathrm{Fe}$}

Penentuan Fe dilakukan agar limbah cair AAS tidak mencemari lingkungan sebelum di buang ke lingkungan sekitar. Untuk itu perlu dilakukan pengolahan agar $\mathrm{Fe}$ sebelum dibuang ke sistem perairan tidak mencemari lingkungansekitar.

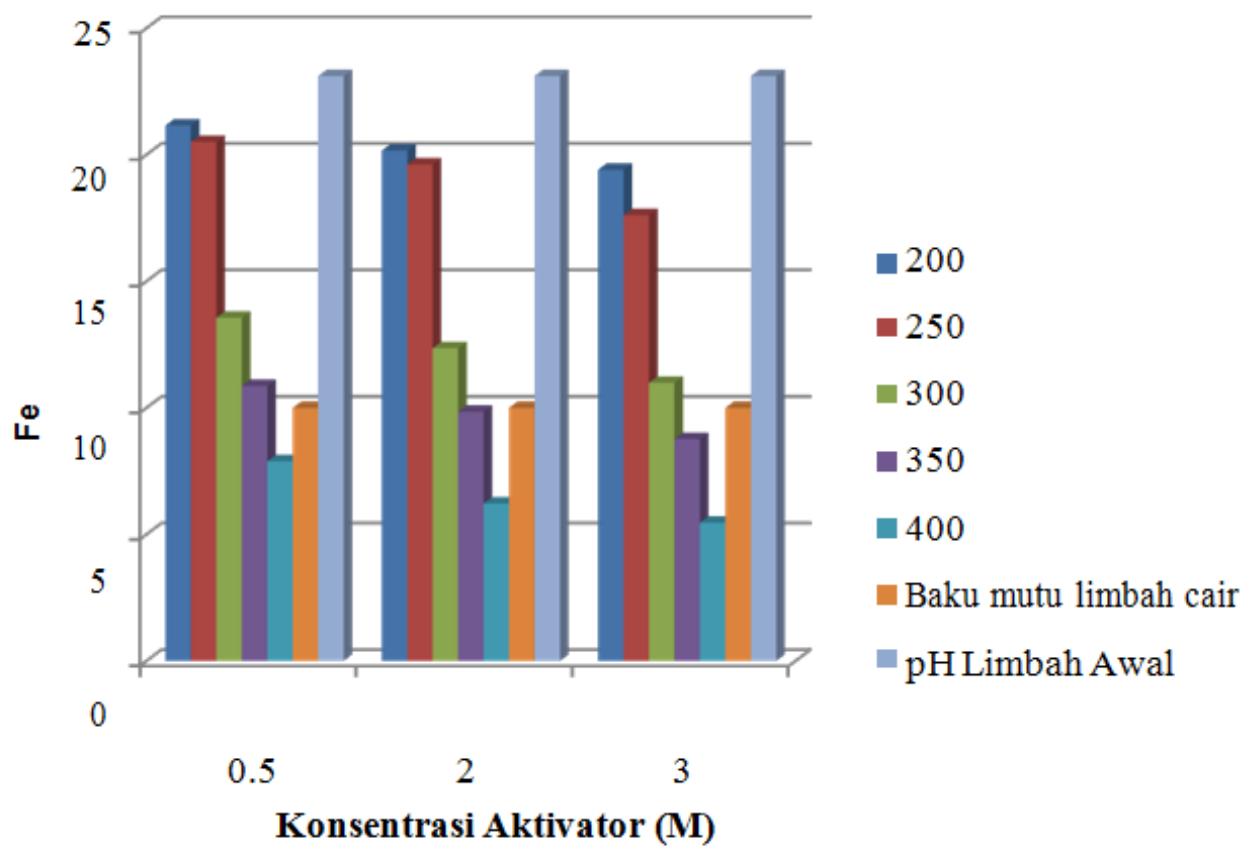

Gambar 9. Hubungan Antara konsentrasi aktivator dengan Fe

Dari gambar 9 grafik diatas terlihat semakin tinggi suhu pengkarbonan dan semakin tinggi konsentrasi activator maka semakin rendah pula nilai Fe pada limbah, hal ini terlihat dari mulai suhu pemanasan $350-400{ }^{\circ} \mathrm{C}$ dan konsentrasi 0,5M, 2,0M, 3,0 M dengan berkisar 9,45-5,46 mg/L, Fe limbah awal 23,11 mg/L dan pada baku mutu limbah cair kementrian negara lingkungan hidup No. KEP51/MENLH/10/1995 sebesar $10 \mathrm{mg} / \mathrm{L}$.

Proses adsorpsi yang terjadi pada karbon aktif yaitu proses adsorpsi secara fisika, dimana proses penjerapan ion logam $\mathrm{Fe}^{2+}$ terjadi pada permukaan karbon aktif. Dengan adanya gaya Van Der Waals pada pori-pori karbon aktif maka partikel pencemar yang terdapat pada limbah tertarik dan terperangkap pada pori- pori karbon aktif (Hendra, 2008), sehingga ion logam $\mathrm{Fe}^{2+}$ pada limbah menjadi berkurang. 
Berdasarkan penelitian Fajarwati (2012) karbon akif mampu menurunkan logam Fe pada pengolahan air tanah sebesar 59,64\% dari 3,03 mg/l menjadi $1,22 \mathrm{mg} / \mathrm{l}$, sedangkan pada penelitian ini penurunan logam Fe terjadi sebesar $62,25 \%$ dari 19,4 menjadi $7,324 \mathrm{mg} / \mathrm{l}$. Hal ini dikarenakan pada penelitian Fajarwati (2012) sistem yang digunakan pada pengolahan adalah sistem continuesehinggawaktu kontak air dengan adsorben tidak lama. Sedangkan pada penelitian ini, menggunakan sistem batch, dimana waktu kontak antara limbah dan adsorben lebih lama dibandingkan penelitian Fajarwati (2012), karena suatu adsorben memerlukan waktu untuk mencapai kesetimbangan dalam menjerap beban pencemar.

Sedikitnya jumlah karbon aktif yang digunakan dalam proses adsorpsi merupakan faktor yang menyebabkan logam Fe pada limbah masih berada di atas baku mutu yang telah ditentukan. Selain itu ukuran karbon aktif yang digunakan pada penelitian ini tidak sama juga dapat mempengaruhi luas permukaan pori-pori karbon aktif. Semakin besar pori-pori karbon aktif, maka semakin banyak pula partikel yang teradsorpsi.

\section{KESIMPULAN}

1. Semakin tinggi suhu pengkarbonan dan semakin tinggi konsentrasi asam akan berpengaruh pada analisa limbah pada AAS yaitu pada suhu pengkarbonan $400{ }^{\circ} \mathrm{C}$ dan konsentrasi activator $3,0 \mathrm{M}$

2. Karbon aktif yang memenuhi syarat Standar Nasional Indonesia (SNI 06- 3730-1995) dan baku mutu limbah cair kementrian negara lingkungan hidup No. KEP-51/MENLH/10/1995 pada variabel suhu pemanasa 350-400 dan konsentrasi 0,5 M, 2,0 M, 3,0M

3. Karbon aktif yang dihasilkan pada limbah:

- $\mathrm{pH}$ awal 0,34 dan variabel yang mendekati pH dengan baku mutu limbah cair kementrian negara lingkungan hidup No. KEP- 51/MENLH/10/1995 yaitu6,0-9,0

- Fe awal 23,11 mg/L dan $350-400{ }^{\circ} \mathrm{C}$ dan konsentrasi 0,5M, 2,0M, 3,0 M dengan berkisar 9,45-5,46 mg/L, Fe limbah awal $23,11 \mathrm{mg} / \mathrm{L}$ dan pada baku mutu limbah cair kementrian negara lingkungan hidup No. KEP-51/MENLH/10/1995 sebesar 10mg/l.

\section{SARAN}

1. Untuk penelitian selanjutnya dapat dilakukan dengan memvariasikan waktu perendaman aktivator agar mendapatkan karbon aktif yang mempunyai daya seraptinggi.

2. Untuk pembuatan karbon aktif yang digunakan untuk mengolah limbah yang bersifat asam maka digunakan aktivator yang bersifat basa dan juga sebaliknya.

3. Analisa komposit karbon aktif dapat ditambahkan uji FTIR atau EDS agar dapat terlihat jumlah carbon di dalam karbon aktiftersebut.

4. Pemilihan bahan baku tongkol jagung kurang cocok untuk kulitas karbon aktif karena tingginya volatile metter sebaiknya diganti bahanlain.

\section{DAFTAR PUSTAKA}

Ade, firmansyah dkk, 2012, Jurnal Analisis Kadar Logam Berat Timbal Di Mata Air pegunungan Guci dengan Metode Spektrofotometri Serapan Atom, Universitas Muhammadiyah,Purwokerto.

Audiana, Mia, dkk, Jurnal Pengolahan Limbah Cair Laboraturium Teknik Lingkungan Dengan Koagulasi Adsorpsi untuk menurunkan COD, Fe, dan $\mathrm{pB}$

Azamia, Mia, 2012, Skripsi, Pengolahan Limbah Cair Laboraturium Teknik Lingkungan Dengan Koagulasi Dan Adsorpsi Untuk Menurunkan COD, Fe, DAN Pb, Universitas Indonesia 
Arista Ningsih Dwi, dkk, 2016. Jurnal Adsorpsi Logam Timbal (Pb) Dari Larutan Dengan Menggunakan Adsorben Dari Tongkol Jagung. Diterbitkan di bulan Juni 2016.

Brady, J. E. 1999. Kimia Universitas Asas dan Struktur. Binarupa Aksara. Bandung

Fajarwati, I. 2015. "Pengolahan Air Tanah Dengan Sistem Multifiltrasi Menggunakan Cangkang Kerang, Zeolit, Dan Karbon Aktif”. Jurnal Mahasiswa S1 Teknik Lingkungan: Vol. 1, No. 1. UNTAN. Pontianak.

Kirk and Othmer. 1964. Encyclopedia of Chemical Technology. Vol.4. p.71. John Wiley Sons, Inc, New York.

Kurniati, Elly. 2008. Pemanfaatan Cangkang Kelapa Sawit Sebagai Arang Aktif. Teknik Kimia FTI, UPN. Jawa Timur.

Peraturan Pemerintah Kementrian Negara Lingkungan Hidup No. KEP- 51/MENLH/10/1995

Purwanto, Djoko. 2011. Arang Dari Limbah Tempurung Kelapa Sawit.Banjarbaru:Jurnal Penelitian Hasil Hutan.

Prameidia, Monika Dwi. 2013. "Pengaruh Konsentrasi Aktivator H2SO4 Terhadap Daya Serap Karbon Aktif dar Cangkang Kelapa Sawit".

Rumidatul, Alfi. 2006. Efektivitas Arang Aktif Sebagai Adsorber Pada Pengolahan Air Limbah. Bogor: Pascasarjana Institut Pertanian Bogor.

Setiaty Pardia, dkk. 2016. Jurnal Teknik Kimia USU Vol. 5 No. 4 Tahun 2016.UniversitasSumatera Utara. Medan.

Sembiring, Meilita Tryana. Sinaga, Tuti Sarma. 2003. Arang Aktif (Pengenalan dan ProsesPembuatannya). Sumatera Utara: Jurusan Teknik Industri Universitas Sumatera Utara.

Salamah, Siti. 2008. Pembuatan Karbon Aktif Dari Kulit Buah Mahoni Dengan Perlakuan Perendaman Dalam Larutan KOH. Yogyakarta:Teknik Kimia Universitas Ahmad Dahlan.

Smisek, M. \& Cerny S. 1970. Active Carbon Manufactute Properties and Aplication. Amsterdam: El Savier Publishing Company.

Suprapto, H.S. dan Rasyid, M.S. (2002). Bertanam Jagung. Penebar Swadaya, Jakarta.

Sunardi.(2010) Penuntun Praktikum Kimia Analisa Instrumentasi . Depok Departemen kimia Fakultas MIPA Universitas Indonesia

Tutik dan Faizah H. 2001. "Aktivasi Arang Tempurung Kelapa Secara Kimia dengan Larutan Kimia $\mathrm{ZnCl} 2, \mathrm{KCl}$ dan HNO3". Jurusan Teknik Kimia UPN. Yogyakarta 